\title{
Prognostic Indicators in Patients with Intracerebral Hematoma in an Urban Clinical Setting of a Resource Limited Country
}

\author{
Hugues Ghislain Atakla $M B B S^{1}$ iD, Fatoumata Lounceny Barry $M B B S^{2}$ iD, Mahugnon Maurel Ulrich Dénis \\ Noudohounsi $M B B S^{3}$ iD, Benjamin Bekoe Ofosu $M B B S^{4}$ iD, Sulaimi Sulemana Ummi $M B B S^{5}$ iD, Dismand Stephan \\ Houinato $M D^{6}$ iD \\ 1,6Neurology Department, University Hospital Center Hubert Koutoukou MAGA, Cotonou, Benin \\ ${ }^{1,6}$ Laboratory of Noncommunicable and Neurologic Diseases Epidemiology, Faculty of Health Science, University of \\ Abomey-Calavi, Cotonou, Benin \\ ${ }^{2}$ Neurosurgery Department, University Hospital Center, Conakry, Guinea \\ ${ }^{3}$ Monitoring and evaluation/WHO AFRO, Research Project Manager, Brazzaville, Congo \\ ${ }^{4,5}$ Intensive Care Unit, MAB International Clinic, Accra, Ghana
}

Date of submission: $28^{\text {th }}$ April 2021

Date of acceptance: $14^{\text {th }}$ November 2021

Date of publication: $1^{\text {st }}$ December 2021

\section{Abstract}

Introduction: Hemorrhagic Cerebrovascular Accident represents 10 to $15 \%$ of all strokes and are often related to the spontaneous rupture of small vessels weakened by chronic arterial hypertension, amyloid angiopathy, tumor bleed, arteriovenous malformation (AVM), and coagulopathies. The aim of this study was to determine probable prognostic indicators in functional outcomes of patient with ICH.

Materials and Methods: This was a retrospective analytical study of patients (men and women, of all ages) who were hospitalized at the Neurology Department of the University Hospital of Conakry for an intracerebral hematoma over the 24-month period. Only the records of patients in whom intracerebral hematoma was confirmed by brain imaging were included in this study. The variables studied were epidemiological, clinical, and para-clinical. Therapeutic, evolutionary and prognostic variables were also taken into account. Logistic regression (univariate and multivariate) was used to identify the prognostic determinants of intracerebral hematomas at $p<0.05$. Data were entered using Epi Info software version 7.1.4.0 and then analyzed using STATA/SE software version 11.2.

Results: We collected 105 cases of spontaneous cerebral hematomas confirmed by brain imaging out of 491 patients with stroke $(21 \%)$. There was a male predominance of $60 \%$. Arterial hypertension was identified as the cause in 94 patients $(89.52 \%)$, followed by arteriovenous malformations in $6.67 \%, 2.86 \%$ amyloid angiopathy and $0.95 \%$ of unknown cause. During the hospitalization of the patients, we recorded $20 \%$ of deaths. Poor prognosis was associated with length of stay for $\geq 10$ days $(p=0.001)$, hematoma volume $(p=0.02)$, GCS $<7(p=0.001)$ and high ICH score $(\mathrm{p}=0.0001)$.

Conclusion: Premorbid physical condition and comorbidities affects the prognostic course in patient with ICH and should be taken into account in the prediction of disability and future quality of life.

Key words: Guinea, Intracerebral hematomas, Limited health resources, Prognosis.

Access this article online

Website: https://www.nepjol.info/index.php/NJN

DOI: https://doi.org/10.3126/njn.v18i4.36701

HOW TO CITE

Atakla HG, Barry LF, Noudohounsi MMUD, Ofosu BB, Ummi SS,

Houinato DS. Prognostic Indicators in Patients with Intracerebral

Hematoma in an urban clinical setting of a resource limited

Country. NJNS. 2021;18(4):33-8.

\section{Introduction}

Spontaneous cerebral hematoma is a specific type of stroke. They correspond to a bleeding in the cerebral parenchyma that can extend to the cerebral ventricles. ${ }^{1}$ They represent 10 to $15 \%$ of all strokes ${ }^{2}$ and are often related to the spontaneous rupture of small vessels

Copyright (C) 2021 Nepalese Society of Neurosurgeons (NESON)

ISSN: 1813-1948 (Print), 1813-1956 (Online)

Address for correspondence:

Hugues Ghislain Atakla

Neurology,

National University Hospital Center

Hubert Koutougou, MAGA

Cotonou, Benin

Phone: +22997492211

(i) (8) This work is licensed under a Creative Commons

E-mail: neuroscience.ghislain@gmail.com 
weakened by chronic arterial hypertension or amyloid angiopathy. ${ }^{3}$ More rarely, hemorrhage is secondary to rupture of a vascular malformation, tumor, venous thrombosis, hemorrhagic transformation of an arterial infarct, cavernoma, cerebral phlebitis, coagulopathy, or anticoagulant medication. ${ }^{3,4}$

Spontaneous cerebral hematomas are responsible for 30 to $50 \%$ of deaths and nearly $80 \%$ of patients are dependent at six months. ${ }^{3}$ It is not related to gender and its frequency increases with age and half of the deaths occur within the first 48 hours. ${ }^{5}$ The clinical presentation is conditioned by the location of the hematoma. Deep hematomas (basal ganglia) are responsible for sensory and/or motor deficits in the hemisphere contralateral to the lesion. ${ }^{6}$ While lobar bleeds are most often responsible for coma. Sub-tentorial hematomas are less frequent than supra-tentorial hematomas. ${ }^{6}$ Close monitoring is warranted to assess the consequences of the oedema generated and look for signs of intracranial hypertension and for evidence of secondary hydrocephalus. ${ }^{7}$ Diagnosis is made by brain imaging. ${ }^{5}$

In the acute stage, the haematoma is typically hyperdense with peri-lesional oedema. ${ }^{4}$ The aim of treatment is to minimize the risk of further bleeding and the consequences of intracranial hypertension. ${ }^{8}$ The prognosis of $\mathrm{ICH}$ at six months is much less favourable because they cause severe neurological sequelae with only $20 \%$ of patients being independent at six months. ${ }^{9}$ Recovery of motor disability is assessed by the Rankin score.

The Rankin handicap scale was developed to prognosticate patients with stroke. ${ }^{9,10}$ Certain clinical and radiological indicators, including Hemphill's "ICH Score" or cerebro-meningeal hemorrhage score, predict mortality at 30 days and functional prognosis at one year. A modified ICH Score of less than 2 is an excellent predictor of good prognosis. ${ }^{5}$ The NIHSS (Stroke Severity Scale) score is a better predictor of morbidity. ${ }^{5,11}$

This series allows us to evaluate the prognosis of intracerebral hematomas at the neurology department of Ignace Deen University Hospital Center in Conakry.

\section{Materials and Methods}

This was an analytical retrospective study, conducted on all patients who were hospitalized for an intracerebral hematoma over a period from January 1, 2017 to December 31, 2019. All records of patients hospitalized with intracerebral hematoma confirmed by brain CT and/or brain MRI were included in this study. We did not include records of patients who had intracerebral hematoma but refused to participate in the study, and patients who we could not reach to reassess the prognosis. The following data were collected: age, sex, socio- professional strata, marital status, origin, history, risk factors, secondary systemic brain injury (SSBA), mode of onset, time to consultation, etiologies, initial assessment of stroke severity, complications, therapeutic variables, evolutionary variables and prognosis.

\section{Initial assessment of the severity of intracerebral hematoma}

The assessment of severity was done mainly by a clinical scale, the NIHSS (National Institute Heath Stroke Scale) score, and by prognostic factors mainly studied in the situation of severe stroke. The NIHSS scale is rated from 0 (normal) to 42 (maximum score). It is composed of 11 items exploring consciousness, oculomotricity, visual field, motor skills, sensitivity, ataxia, language and neglect. ${ }^{6}$ A stroke is defined as:

- Minor if the score is between [0 and 5]

- Moderate for a score between [6 and 10].

- Severe if the score is between [11 and 15].

- Very severe if the score is between [16 and 20].

- $\quad$ Severe for a score higher than 20.

The evolutionary variables (favorable and death) were defined by the following criteria:

- NIHSS score at admission: was used to assess the severity of acute stroke and a fairly reliable predictor of residual disability.

- Hematoma volume: was calculated according to the formula $\mathrm{AxBxC} / 2$ and expressed in milliliters ( $\mathrm{A}$ is the largest diameter of the hematoma, $\mathrm{B}$ is the largest diameter perpendicular to $\mathrm{A}$ on the same slice, $\mathrm{C}$ is the product of the number of slices in which the hematoma is seen by the thickness of the slices). The average size of the hematoma was determined

- ICH scores at admission: performed at admission has a predictive value for one-month mortality (table 1):

- RANKIN admission score: this was performed on all our patients. It is a global evaluation scale of handicap, performed in 5 minutes. This score allows us to classify hemiplegic patients into six categories according to their ability to walk and their dependence on activities of daily living:

0 : No symptoms

1: No disability apart from symptoms: activities and autonomy maintained

2: Low disability: inability to perform usual activities but autonomy

3: Moderate disability: needs help but can walk without assistance

4: Moderately severe disability: walking and daily activities impossible without assistance

5: Major disability: permanent bed rest, incontinence and permanent nursing care

6: Death 
The information collected in this study was obtained with the consent of the patients and/or their parents. The anonymity and confidentiality of the information collected were preserved. All the data were entered using Epi Info software version 7.1.4.0 and then analyzed using STATA/ SE software version 11.2.

\section{Results}

During the study period, we collected 105 cases of spontaneous cerebral hematomas confirmed by brain CT and brain MRI, out of a total of 491 stroke patients, representing an incidence of $21 \%$.

There was male predominance of $60 \%$ among the study group. The mean age was $56 \pm 15$ years with extremes of 22 and 93 years. The age group most affected by the disease was that between 60 and 70 years with 25 patients or $23.81 \%$. We noted a clear predominance of married patients with $96 \%$, followed by widows with $6.67 \%$, singles and widowers respectively $0.95 \%$. Seventy-three (73\%) of the patients were from urban areas, compared to $27 \%$ from rural areas. Of the 105 patients analyzed in this series, $89(84.76 \%)$ had a comorbidity of arterial hypertension, 10 (9.52\%) had type II diabetes, 5 (4.76\%) had a previous ischemic stroke and only $1(0.96)$ patient had heart disease.

At admission, 39 patients (37.14\%) had an NIHSS score of $11-15$; $36(34.29 \%)$ had an NIHSS score of 16-
20 . Only 5 or $4.76 \%$ of the patients had an NIHSS score of 0 - 5, i.e. a mean NIHSS score of $14.18 \pm 4.72$.

All patients had a brain CT scan and among them, 30 patients $(28.57 \%)$ also had a brain MRI scan. The deep location was found in sixty-five (65) or $61.9 \%$ of patients, 13 or $12.38 \%$ lobar, 12 or $11.43 \%$ in the brainstem and intraventricular in 15 or $14.29 \%$ of cases with associated lesions in 17 cases or $15 \%$. We found associated lesions in 17 patients, including 12 cases of involvement (11.43\%), 6 cases of mass effect $(5.71 \%)$ and 5 cases of ventricular dilatation $(4.76 \%)$. The mean volume of the hematoma was $43.19 \mathrm{ml} \pm 35.047$. 69.52\% patients had volume $\leq$ $30 \mathrm{ml}$.

The functional prognosis of our patients were assessed by the Rankin score. 81 patients equivalent to $77.14 \%$ had a Rankin score of 4 on admission, followed by 13 or $12.38 \%$ with a score of 3 ; only 1 patient or $0.95 \%$ had a score of 6 , with a mean Rankin score of $3.85 \pm 0.68$ on admission.

47 patients or $44.76 \%$ had an admission ICH score of 2; 25 patients or $23.81 \%$ had an ICH score of 1 and 3 respectively; 2 or $1.90 \%$ had a score of 4 and only 1 patient had a score of 5 , the mean admission ICH score was $1.97 \pm 0.91$. Hyperthermia and hyperglycemia were the secondary brain attacks of systemic origin occurring during hospitalization, distributed respectively in the following proportions: 39 patients $(37.14 \%), 24$ patients $(22.86 \%)$. Other complications which occurred during hospital stay are shown in Table 2.

\begin{tabular}{|c|c|c|}
\hline \multicolumn{3}{|c|}{ HEMPHILL'S SCORE (ICH) } \\
\hline CRITERIA & & SCORES \\
\hline \multirow{3}{*}{ Glasgow coma scale } & $3-4$ & 2 \\
\hline & $5-12$ & 1 \\
\hline & $13-15$ & 0 \\
\hline \multirow{2}{*}{ Volume of the hematoma } & $\geq 30 \mathrm{ml}$ & 1 \\
\hline & $<30 \mathrm{ml}$ & 0 \\
\hline \multirow{2}{*}{ Ventricular effusion rate } & Oui & 1 \\
\hline & Non & 0 \\
\hline \multirow{2}{*}{ Age (years) } & $\geq 80$ ans & 1 \\
\hline & $<80$ ans & 0 \\
\hline \multirow{2}{*}{ Infratentorial topography } & Yes & 1 \\
\hline & No & 0 \\
\hline \multicolumn{3}{|c|}{ Mortality at 30 days } \\
\hline$\geq 5$ & & $100 \%$ \\
\hline 4 & & $97 \%$ \\
\hline 3 & & $72 \%$ \\
\hline 2 & & $26 \%$ \\
\hline 1 & & $13 \%$ \\
\hline 0 & & $0 \%$ \\
\hline
\end{tabular}

Table 1: HEMPHILL'S SCORE (ICH) 


\begin{tabular}{l|c|c}
\hline \multicolumn{1}{c|}{ Complications } & n & Percentage (\%) \\
\hline Pressure ulcer & 5 & 4.76 \\
\hline Inhalation pneumopathies & 15 & 14.28 \\
Septic shock & 3 & 2.85 \\
Recurrence & 0 & 0 \\
\hline Pulmonary embolism & 2 & 1.90 \\
\hline
\end{tabular}

Table 2: Distribution of patient folder according to complications during hospitalization.

The evolution was favorable in 84 patients or $80 \%$ in contrast to 21 patients or $20 \%$ death (Figure 2). Length of stay $\geq 10$ days was associated with high mortality ( $p$ $=0.001)$. Hematoma volume was associated with high mortality $(p=0.02)$. GCS score $<7$ on admission was correlated with high mortality $(p=0.001)$. In this study the high ICH score was associated with high mortality, we found a significance threshold $(\mathrm{p}=0.0001)$.

\section{Discussion}

Our study found an overall frequency of $21 \%$. Our numbers are higher to those of Basse et al in $2017^{2}$ who found 10 to $15 \%$ of strokes.

Our cohort had male predominance of $60 \%$. Our result is similar to that of COLNAT-COULBOIS S. et al. at Nancy University Hospital in France, who reported a clear male predominance of $62 \%{ }^{12}$. This result could be explained in our context by the fact that the male sex is most exposed to cardiovascular risk factors before the age of 55 or less.

The mean age of our patients was 15.12 years with extremes of 22 and 93 years. The most affected age group was between 60 and 70 years old. Our results are consistent with those of Bilongo Manene ${ }^{13}$ who found a mean age of 61 years. These results show that the incidence of hemorrhagic stroke increases with age.

We noted a clear predominance in married patients with $96 \%$ followed by widows with $6.67 \%$, singles $0.95 \%$. This result is comparable to that of Sene Diouf. F et al. at Fann University Hospital in Dakar ${ }^{14}$ who reported 35 (68.5\%) married cases followed by 9 (17.6\%) widowed cases. This could be explained by the fact that married people are more exposed to family stress than unmarried people.

At admission 39 patients or $37.14 \%$ had an NIHSS score between $11-15 ; 36$ patients or $34.29 \%$ had an NIHSS score of 16 - 20. Only 5 or $4.76 \%$ of the patients had an NIHSS score between 0 and 5 with a mean NIHSS score of $14.18 \pm 4.72$. These results are higher than those of CISSE F.A et $\mathrm{al}^{15}$ who found a mean NIHSS score of 10.6 \pm 4.3 .

Deep localization was found in 65 patients $(61.9 \%)$, lobar in $13(12.38 \%)$, brain stem in $12(11.43 \%)$ and intraventricular in $14.29 \%$. Associated lesions were found in 17 patients, including 12 cases of engagement (11.43\%), mass effect (5.71\%) (mass effect 6) and 5 cases of ventricular dilatation $(4.76 \%)$. Our results are similar to those of Kanté $\mathrm{M}^{16}$ which found $48.6 \%$ deep localization, 29.2\% lobar localization, 9.7\% brain stem and intraventricular localization in $12.9 \%$, with associated lesions in $15.3 \%$.

The mean volume of the hematoma was $43.19 \mathrm{ml} \pm$ 35.047. This result is close to that of Lelo Tshikwela et $\mathrm{al}^{17}$ who found a mean volume of the hematoma of $37 \mathrm{ml}$.

Hypertension was the cause found in $89.52 \%$ of patients; followed by arteriovenous malformations in $6.67 \%$ of patients, $2.86 \%$ amyloid angiopathy and $0.95 \%$ unknown cause. Jayantee Kalita et al in India ${ }^{18}$ reported $79.2 \%$ of cases of hypertension as the first cause of ICH.

All patients followed physiotherapy sessions for the rehabilitation of hemiplegia. Forty patients, i.e. $38.09 \%$, underwent medicalized rehabilitation; 35 , i.e. $33.33 \%$ of the patients underwent mixed rehabilitation and 30 , i.e. $28.57 \%$ underwent non-medicalized rehabilitation. Our result is different from that of Sene Diouf et al. in Dakar ${ }^{14}$ who reported in their study $53.5 \%$ of cases of rehabilitation carried out by qualified personnel; $29.4 \%$ by unqualified personnel and $24.1 \%$ by a family member. This result could be explained by the fact that unlike developed countries where the treatment of hemiplegia of vascular origin is global and multidisciplinary, in developing countries it is limited to physiotherapy sessions. Occupational therapy is almost non-existent and speech therapy rehabilitation is rare and only exists in private practice. ${ }^{14}$

Evaluation of the functional prognosis of our patients was assessed by the Rankin score. 81 patients or $77.14 \%$ had a Rankin score of 4 at admission, followed by 13 or $12.38 \%$ had a score of 3 ; only 1 patient or $0.95 \%$ had a score of 6 , with a mean Rankin score at admission of 3.85 \pm 0.68 . On admission, $44.76 \%$ of patients had an $\mathrm{ICH}$ score of $2 ; 25$ patients or $23.81 \%$ had an ICH score of 1 and 3 respectively; 2 or $1.90 \%$ had a score of 4 and only 1 patient had a score of 5 . The mean ICH score at admission was $1.97 \pm 0.91$. Our result is superior to that of A. Gnazebo et al ${ }^{19}$ who found an $\mathrm{ICH}$ score that varied between $(0$ and 4) with a mean ICH score of 1 . The volume of the haematoma was associated with high mortality with a $\mathrm{p}$ value $=0.02$. This result is comparable to that of Capellari et al. in $2015^{20}$ who reported a hematoma volume $\geq$ of 30 $\mathrm{ml}$ with a significance threshold $<0.001$.

The Glasgow score $<7$ at admission correlated with high mortality with a significance value $\mathrm{p}=0.001$. Rasamoelina $\mathrm{N}$ et al in 2018 in their study reported that the Glasgow score $\leq 8$ was correlated with high mortality with a significance value of $p=0.03 .{ }^{21}$ Our result could be explained by the fact that the management of intracerebral hematomas in the neurovascular unit during the acute phase would considerably reduce their mortality. In this work, 
the high ICH score was associated with high mortality, and we found a threshold of significance with a value of $p=0.0001$. This result could be explained by the fact that the components of the $\mathrm{ICH}$ score are predictive factors associated with high mortality during ICH. The evolution was favourable in 84 patients, i.e. $80 \%$ as opposed to 21 patients, i.e. $20 \%$ of deaths. This high mortality rate could be explained by the fact that our deceased patients had an ICH score between ( 3 and 5) on admission. This result could be explained by the fact that an extended hospital stay increases the risk of medical complications.

Many studies describe the functional prognosis and early complications of intracerebral hematomas. However, very little work has been done in this area in developing countries such as ours. We believe that a future study on the follow-up of the CT evolution of intracerebral hematomas will facilitate a better understanding of the matter and guide the clinician in therapeutic decisions.

\section{Conclusion}

Spontaneous brain hematomas usually have poor prognosis with severe neurological sequelae. Morbidity and mortality are largely influenced by complications in the acute phase. Age above 80 years; NIHSS score above 15 at admission; and the occurrence of pressure ulcers and inhalation pneumopathies were factors in poor prognosis. Education of the population to seek medical help at the onset of the first signs is necessary. The organization of care channels and an early start of functional rehabilitation are key elements of good prognosis. Finally, previous autonomy and comorbidities also modify the prognosis and should be taken into account in the prediction of disability and future quality of life.

\section{Acknowledgement}

The authors would like to thank the patients and the ethics committee for consenting to this study.

Conflict of Interest: None

Source(s) of support: None

\section{References}

1. Qureshi Ai, Tuhrim S, Broderick JP, et al. Spontaneous intracerebral hemorrhage. N Engl J Med. 2001;344(19):1450-60. https://doi.org/10.1056/ NEJM200105103441907

2. Basse AM, Sow AD, Toure K, et al. Épidémiologie de l'accident vasculaire cérébral hémorragique chez les patients hospitalisés à la clinique neurologique du CHU de Fann (Dakar). Revue neurologique.
2017;173S:S81-S132. https://doi.org/10.1016/j. neurol.2017.01.149

3. Crozier S. Traitement des hémorragies Cérébrales. La Presse Médicale 2007;36(1):142-149. https://doi. org/10.1016/j.lpm.2006.10.022

4. Hamon M, Leclerc X, Oppenheim C, Gauvrit Jy., Meder Jf., Pruvo JP. Sémiologie TDM et IRM des hématomes intracérébraux : évolution chronologique. Rev Neurol(Paris) 2005;161:10,997-1006. https:// doi.org/10.1016/S0035-3787(05)85167-7

5. Hermitte Y, Do-Esposito S, Foudi H., Tazarourte $\mathrm{K}$, Accident vasculaire cérébral hémorragique. 53 congrès national d'anesthésie et de réanimation. Infirmiers. Infirmier(e)s d'urgence 2011 Sfmu

6. Chung CS, Caplan LR., Han W et al. Thalamic hemorrhage. Brain. 1996;119(Pt 6):1873-86. https:// doi.org/10.1093/brain/119.6.1873

7. Kumral E, Kocaer T. Thalamic hemorrhage A prospective study of 100tients. Stroke. 1995;26(6):964-70. https://doi.org/10.1161/01. STR.26.6.964

8. Mayer SA, Rincon F. Treatment of intracerebral hemorrhage. Lancet Neurol. 2005;4(10):662-72. https://doi.org/10.1016/S1474-4422(05)70195-2

9. Agency for Health Care Policy Research. Post-stroke rehabilitation: assessment, referral, and patient management. Quick reference guide for clinicians. Rock-ville (MD): AHCPR; 1995

10. Duncan P, Lai S, Van Culin V, et al. Development of a comprehensive assessment toolbox for stroke. Clin Geriatr Med. 1999;15(4):885-915. https://doi. org/10.1016/S0749-0690(18)30037-5

11. Teitelbaum J, Scarborough F, et François S. Le Médecin du Québec. volume 41, numéro 6, juin 2006.

12. Morgensen. LB, Anderson G, Hemphill et al. Guidelines for the management of spontaneous Intracerebral. Stroke 2010; 41:2108- 2129. https:// doi.org/10.1161/STR.0b013e3181ec611b

13. Bilongo-Manene B. Mortalité et morbidité des AVC dans le service d'anesthésie réanimation du CHU Gabriel Touré. These, Med, Bamako, 2007; n¹37.

14. Sene Diouf F, Mapoure NY, Ndiaye M et al. Pronostic des hémorragies intracérébrales avec coma dans une unité de neuroréanimation tropicale. Med Trop 2008; $68: 606-610$.

15. Cisse FA, Balde AT, Sakadi Foksouna et al. Hématomes intracérébraux : 129 cas observés au service de neurologie du CHU de Conakry. revue neurologique 2018;174:S55-S108. https://doi. org/10.1016/j.neurol.2018.01.182

16. Kanté $\mathrm{M}$; Pronostic des hématomes intracérébraux spontanés au service de neurologie de l'hôpital 


\section{Atakla et al}

Ignace Deen. thèse de doctorat en médecine service de neurologie CHU Conakry 2014.

17. Lelo Tshikwela M, Longo-Mbenza B. Accident vasculaire cérébral hémorragique du noir africain : caractéristiques scanographiques des hématomes intracérébraux à Kinshasa. J Afr Imag Méd 2011; (4), 7: 355-362.

18. Jayantee Kalita, Gourav, Pankaj K, et al. intracerebral hemorrhage in young from a tertiary neurology center in North India; Journal of the Neurological Sciences 2014:336:42-47. https://doi.org/10.1016/j. jns.2013.09.037

19. Gnazebo A, Kouame-Assouan AE, Akani AF et al ; Score ICH et pronostic vital des hématomes cérébraux au service de neurologie du CHU de Bouaké. revue neurologique 2018;174:S55-S108. https://doi.org/10.1016/j.neurol.2018.01.181

20. Cappellari M, Zivelonghi C, Moretto G, et al, The etiologic subtype of intracerebral hemorrhage may influence the risk of significant hematoma expansion; Journal of the Neurological Sciences 359 (2015) 293297. https://doi.org/10.1016/j.jns.2015.11.024

21. Rasamoelina N, Andrianimaro FM, Randriamarolahy A. Predictive factors of mortality of hemorrhagic stroke observed in the intensive care unit of the teaching hospital tambohobe, fianarantsoa. Paripex - Indian Journal of Research. Volume-7 | Issue-1 | January-2018 | Print ISSN No 2250-1991 